\title{
Short Communication: Infraspecific variations in essential oil compositions of Nepeta fissa from Iran
}

\author{
SEYED MEHDI TALEBI ${ }^{1, \varphi}$, MAJID GHORBANI NOHOOJI ${ }^{2}$, MAHBOOBEH YARMOHAMMADI ${ }^{1}$ \\ ${ }^{1}$ Department of Biology, Faculty of Sciences, Arak University. Arak, 38156-8-8349, Iran. Tel.: +98-863-4173317. \\ "email: seyedmehdi_talebi@yahoo.com \\ ${ }^{2}$ Medicinal Plants Research Center, Institute of Medicinal Plants, ACECR, Karaj, Iran
}

Manuscript received: 7 May 2017. Revision accepted: 29 August 2017.

\begin{abstract}
Talebi SM, Nohooji MG,Yarmohammadi M. 2017. Short Communication: Infraspecific variations in essential oil compositions of Nepeta fissa from Iran. Nusantara Bioscience 9: 318-321. Nepeta fissa C.A. Mey. is a member of Mint family (Lamiaceae) and distributed naturally in different regions of Iran. The aim of this investigation was to provide more information about the influence of environmental conditions on the essential oil composition of two populations, Polor and Dizin, of this species. The dry plant samples were submitted to hydrodistillation for $2.5 \mathrm{~h}$, using a Clevenger-type apparatus. The highest amount of essential oil yields (0.2\%) were obtained for Dizin population. Forty-nine compounds, representing 85.9 to $97.80 \%$ of the total essential oils, were separated and identified. In Dizin and Polor populations, the essential oils were characterized by the very high percentage of oxygenated monoterpenes (79.1\%), oxygenated diterpenes $(20.01 \%)$ that constituted the predominant classes, respectively. From the analyzed populations, the major compounds in Dizin population were 1, 8-Cineole, $4 a$ - $\alpha, 7-a, 7 a$ - $a$-Nepetalactone and $2 E$, $4 E$-nonadienal. While, phytol, caryophyllene oxide, E-caryophyllene, and thymol were the core compounds of essential in Polor population. The obtained results showed that environmental conditions are the important factors influencing the yield and also the chemical compositions of essential oils in $N$. fissa. Knowledge of the essential oil chemical composition in relation to ecological factors is a most prominent quality criterion for its marketing and contributes to its valorization as a functional ingredient in food industry.
\end{abstract}

Keywords: Ecological factors, essential oil, Nepeta fissa, population

\section{INTRODUCTION}

Nepeta L. is a genus of Labiatae (Lamiaceae) family, which grows naturally in various regions of the world. Its name has been taken of the ancient Italian city Nephi. This genus has about 280 taxa occurs all over the world but extensively grown in various parts of Africa, Asia, North America, Central and also the southern part of Europe (Pojarkova 1954). Recently, Jamzad (2012) listed seventynine species of the genus from Iran. Nepeta fissa C.A Mey is a widespread species of the genus. This species has various synonym names, such as $N$. microphylla Stapf, $N$. trautvetteri Boiss. \& Buhse., N. carmanica Bornm. and $N$. teucriifolia sensu Boiss. (Mozaffarian 1996).

The essential oils that found in aromatic herbs are a mixture of various compounds such as monoterpenes, sesquiterpenes and also phenylpropanoids. The great diversity of terpenes in plant species is partly attributable to the existence of terpene synthases, which can manufacture different compounds from a single substrate (Degenhardt et al. 2009; Dudareva et al. 2013). Former studies (e.g. Figueiredo et al. 2008; Lakusic et al. 2012) demonstrated populations of the same species collected from various habitats have different essential oil composition. Therefore, it seems that essential oils biosynthesis is under the influence of multitude abiotic as well as biotic agents.
Zouari (2013) stated various factors, such as climatic, geographic conditions, and ontogeny of selected plants may severely affect the yield of essential oil, its composition, and its biological qualities. For these reasons, examinations of the chemical variability of essential oil in relation to ecological factors can provide data on what determines chemical polymorphism of essential oil. Moreover, understanding of the essential oil chemotype in various plant taxa is a very prominent property criterion for its marketing and contributes to its commercialization as functional ingredients in different industries like food and phytopharmacy.

Yet, different infraspecific studied were carried out on essential oil variations. For example, Marčetić et al. (2013) examined the variability of root essential oil in seven natural populations of Seseli rigidum Waldst. \& Kit. They observed three groups of populations based on climatic differences and found that biosynthesis of terpenes is influenced by different environmental factors.

As far as we could search, we could not find any infraspecific study in the essential oil compositions of $N$. fissa. Therefore, the aims of this work were: A) to study the geographical variability of essential oil and define the chemotypes; and B) to explore the impact of climate on compositions and amount of essential oil. 


\section{MATERIALS AND METHODS}

\section{Populations sampling}

Two populations of $N$. fissa collected from different localities and altitudes in Iran, i.e. Polor, Mazandaran (2400 m asl.) and Dizin, Tehran (2250 m asl.) (Table 1). Twenty individuals from each population were sampled over the entire area of the population at their flowering stage (May 2016). The distance among the selected individuals exceeded $30 \mathrm{~m}$, to avoid selection from close parents. Then, the fresh plant material was dried in the shade, until mass constancy (14 days).

\section{Essential oil extraction}

The dry aerial parts of plants were submitted to hydrodistillation for $2.5 \mathrm{~h}$, using a Clevenger-type apparatus. The obtained essential oils were dried over with anhydrous sodium sulfate and stored in sealed vials at $-25^{\circ} \mathrm{C}$ until analysis.

\section{Volatile compounds identification}

The essential oil compositions of $N$. fissa were identified by comparing the data of mass spectra with spectra available from the Wiley 275 mass spectra libraries). Further identification confirmations were made referring to data of retention indices (RI) created a series of identified standards of the n-alkanes mixture (C7-C25).

Identification of the compounds of essential oil was based on a gas chromatography (Younglin Acme 6000) Plus instrument equipped with a GC-QP 2010 Plus (Agilent) series mass selective detector in the electron impact ionization mode at $70 \mathrm{eV}$. Components separation was performed on fused silica $(100 \%$ dimethyl polysiloxane) column BP5 $(30 \mathrm{~m} \times 0.25 \mu \mathrm{ID} \times 0.25 \mathrm{~mm}$ film thickness) (Restek, USA), splitless injection; helium was carrier gas at a flow rate of $1 \mathrm{ml} / \mathrm{min}$, injector and FID detector temperatures $300^{\circ} \mathrm{C}$. The temperature of GC oven programmed as follows: initially temperature $50^{\circ} \mathrm{C}$ (isothermal for $5 \mathrm{~min}$ ) maximized to $240^{\circ} \mathrm{C}$ at the rate $3^{\circ} \mathrm{C} / \mathrm{min}$ to (isothermal for $5 \mathrm{~min}$ ) and further maximized at the rate $15^{\circ} \mathrm{C} / \mathrm{min}$ to $300^{\circ} \mathrm{C}$, the final temperature kept for 3 min. Total response time was 75 min.

The silica capillary column BP5 with $30 \mathrm{~m} \times 0.25 \mu$ ID $\times 0.25 \mathrm{~mm}$ film thickness (Thermo Electron Corporation, USA) under the same chromatographic conditions. The percentage amounts of the investigated compounds were recalculated according to the areas of the FID chromatographic peaks assuming that all constituents of the essential oil comprise $100 \%$.

Table 1. Locality address of studied populations of $N$. fissa

\begin{tabular}{ll}
\hline Populations & Localities \\
\hline Polor & Mazandaran province, Haraz road, Polor, $2400 \mathrm{~m}$. \\
Dizin & $\begin{array}{l}\text { Tehran province, Albourz mountain, Protected } \\
\text { area, } 2250 \mathrm{~m} \text { asl. }\end{array}$ \\
\hline
\end{tabular}

\section{RESULTS AND DISCUSSION}

\section{Results}

GC/MS analysis of the essential oils of $N$. fissa collected from Dizin and Polor populations led to the identification of a total of 49 constituents (Table 2). In the essential oil obtained from Dizin population, 32 compounds amounting to $97.80 \%$ of the total oil content were identified. Monoterpenes accounted for $82.44 \%$ of the total oil composition, $79.1 \%$ of that were attributed to oxygenated monoterpenes. Among the oxygenated monoterpenes detected, 1, 8-cineole was the major part $(55.98 \%)$ of the total oil. Other constituents identified in this category were $4 a-\alpha, 7-\alpha, 7 \quad a$ - $\alpha$-nepetalactone $(6.54 \%)$, 1,4-cineole ( $3.93 \%)$ and $4 a-\alpha, 7-\alpha, 7 \quad a-\beta$,-nepetalactone $(2.97 \%)$.Sesquiterpene hydrocarbons were detected in this population $(5.97 \%$ of the total oil content) with $(Z) \alpha$ bisabolene $(3.17 \%)$ and $E$-caryophyllene $(0.87 \%)$ were the main compounds. Oxygenated sesquiterpenes accounted only for $2.69 \%$ of the total oil content and were represented spathulenol $(1.49 \%)$ and caryophyllene oxide (1.20\%). However, in Polor population the chemical composition varied greatly. A total of 26 constituents were identified comprising $85.34 \%$ of the total oil compounds. Oxygenated diterpenes had the highest contribution at this population, accounting for $20.01 \%$ of the total oil content. The major contributor to this category was phytol (20.01\%). The concentration of oxygenated monoterpene decreased compared to the Dizin population $(13.91 \%, 79.01 \%$, respectively).

Thymol $(7.26 \%)$ was the major component between the seven oxygenated monoterpenes detected from the Polor population. The amount of sesquiterpene hydrocarbons increased to $14.43 \%$ of the total oil content, with $E$ caryophyllene $(7.76 \%)$ and germacrene D $(2.15 \%)$ being detected as main constituents of the fraction. Dibutyl phthalate and benzyl benzoate were the only esters detected in the essential oil Polor population at concentrations of 4.29 and $5.31 \%$, respectively.

\section{Discussion}

The amount of yielded essential oil varied between the studied populations. Although, its amount in population Dizin was equal to that was reported by Sefidkon et al. (2002), the essential oil value in Polor population was very low like those were recorded by Baser et al. (2000). The Polor population growing in a higher altitude than Dizin population. It seems that, plants grow at lower altitude yield more essential oil compared with those grown at higher altitude. These conditions were seen in different species. For example, Haider et al. (2009) found that populations of Artemisia roxburghiana grow at higher altitudes yield the lowest amount of essential oil. Moreover, Thymus praecox growing in higher altitudes have lower essential oil than plants grown in lower altitudes (Avci 2011). While, Zouari et al. (2014) in Artemisia saharae (Asteraceae), observed that populations of higher altitudes had the highest amount of essential oil. 
Table 2. Essential oil composition of the studied populations of N. fissa

\begin{tabular}{|c|c|c|c|}
\hline Compounds & RT & Polor & Dizin \\
\hline 1,8-Cineole & 16.94 & 0.6 & 55.98 \\
\hline Linalool & 20.50 & 0.4 & 0 \\
\hline 2-Methoxy-P-Cresol & 26.54 & 1.53 & 0 \\
\hline Thymol & 30.12 & 7.26 & 0 \\
\hline$\beta$-Bourbonene & 33.88 & 0.72 & 0.85 \\
\hline $4 a-\alpha, 7-\beta, 7 a-\alpha$-Nepetalactone & 34.78 & 0.79 & 0 \\
\hline$E$-Caryophyllene & 35.47 & 7.76 & 0.87 \\
\hline (Z)- $\beta$-Farnesene & 36.68 & 0.89 & 0.35 \\
\hline Germacrene D & 38.09 & 2.15 & 0.73 \\
\hline Bicylcogermacrene & 38.71 & 0.77 & 0 \\
\hline$\beta$-Bisabolene & 39.08 & 0.87 & 0 \\
\hline$\delta$-Cadinene & 39.43 & 0.50 & 0 \\
\hline$\beta$-Sesquiphellandrene & 39.79 & 0.77 & 0 \\
\hline Spathulenol & 42.19 & 7.49 & 1.49 \\
\hline Caryophyllene oxide & 42.37 & 8.27 & 1.20 \\
\hline Hexadecane & 42.88 & 0.41 & 0 \\
\hline caryophylla-4(14),8(15)-dien-5. $\alpha$-ol & 44.50 & 0.33 & 0 \\
\hline epi- $\alpha$-Cadinol & 44.64 & 2.63 & 0 \\
\hline Heptadecane & 46.24 & 0.79 & 0 \\
\hline Benzyl Benzoate & 49.54 & 5.31 & 0 \\
\hline Octadecane & 49.81 & 1.23 & 0 \\
\hline 6,10,14-trimethyl-2-oentadecanone & 51.42 & 6.71 & 0 \\
\hline Dibutyl phthalate & 55.53 & 4.29 & 0 \\
\hline Phytol & 60.07 & 20.01 & 0 \\
\hline $3 E$-Hexanal & 8.28 & 0 & 0.23 \\
\hline$\alpha$-Pinene & 11.68 & 0 & 0.43 \\
\hline$\beta$-Pinene & 14.04 & 0 & 0.63 \\
\hline 1,4-Cineole & 16.17 & 0 & 3.93 \\
\hline ortho-Cymene & 16.66 & 0 & 0.82 \\
\hline$\delta$-Terpinene & 18.30 & 0 & 0.33 \\
\hline$\alpha$-Campholenal & 22.05 & 0 & 0.37 \\
\hline trans-Pinocarveol & 22.76 & 0 & 1.73 \\
\hline cis-Verbenol & 23.00 & 0 & 1.14 \\
\hline Pinocarveon & 23.90 & 0 & 0.56 \\
\hline$\delta$-Terpineol & 24.28 & 0 & 1.13 \\
\hline$p$-Mentha-1,5-dien-8-ol & 24.38 & 0 & 0.53 \\
\hline Menthol & 24.60 & 0 & 0.28 \\
\hline Terpinene-4-ol & 24.72 & 0 & 1.12 \\
\hline$\alpha$-Terpineol & 25.52 & 2.32 & 2.32 \\
\hline Verbenone & 26.19 & 0.54 & 0.54 \\
\hline $2 E, 4 E$-Nonadienal & 26.59 & 0 & 5.01 \\
\hline E-Anethole & 29.91 & 0 & 0.42 \\
\hline $4 a-\alpha, 7-\alpha, 7 \quad a-\alpha$-Nepetalactone & 33.16 & 0 & 6.54 \\
\hline $4 a-\alpha, 7-\alpha, 7 a-\beta$-Nepetalactone & 33.48 & 0 & 2.97 \\
\hline Geranyl Acetate & 33.66 & 0 & 0.58 \\
\hline (Z)- $a$-Bisabolene & 38.79 & 0 & 3.12 \\
\hline $4 a-\alpha, 7-\beta, 7 a-\alpha$-Nepetalactone & 34.78 & 0 & 0.79 \\
\hline 6,10,14-Trimethyl-2-Pentadecanone & 51.39 & 0 & 0.36 \\
\hline Manoyl oxide & 56.79 & 0 & 0.45 \\
\hline
\end{tabular}

Sefidkon et al. (2002) studied the essential oil compositions of aerial parts of $N$. fissa collected from Tehran Province, Iran. The major compounds of essential oil in their study were; $\beta$-caryophyllene (17.4\%), caryophyllene oxide $(12.3 \%), \quad \gamma$-muurolene $(7.9 \%)$, valencene $(6.6 \%), \quad \beta$-pinene $(6.0 \%) \quad \alpha$-pinene $(5.8 \%)$, bicyclogermacrene $(4.9 \%)$, spathulenol $(4.1 \%)$. Furthermore, Baser et al. (2000) extracted the essential oil of aerial parts of Turkish population of this species and analyzed it by GC/MS. They reported caryophyllene oxide (24\%) and $P$-caryophyllene $(8.3 \%)$, spathulenol (7.4\%), $\beta$ pinene $(6.8 \%)$ and $\alpha$-pinene $(6.7 \%)$ as the main constituents.

The compositions of essential oil greatly differed between our studied populations. When the obtained results were compared with previous studies (Sefidkon et al., 2002; Baser et al., 2000) on this species, it was observed that the essential oil compositions of the Polor population were more similar to the mentioned investigations than Dizin samples. For example, caryophyllene oxide and $E$ caryophyllene were among the core constituents of Polor population essential oil. These conditions were seen in Sefidkon et al. (2002) as well as Baser et al. (2000) works. But, in the mentioned works, their percentages were lower than Dizin population.

Although, a relative likeness was seen between essential oil compositions of the Polor population with previous works, the main constituents of essential oil of Polor and also Dizin populations highly differed with results of those studies. There are several reasons for these variations, but the edaphoclimatic condition is one of the possible reasons. The plant samples of Turkey grown at an altitude of 1300-1400 m (Baser et al. 2000), while the habitats of our studied populations had more than $2100 \mathrm{~m}$ elevations. Kofidis et al. (2003) demonstrated altitude as one of the abiotic stresses that are associated with changes in a wide range of ecological factors. Furthermore, on the basis of different examinations (e.g. Rahimmalek et al. 2009; Zouari et al. 2012) the altitude induces high variations on essential oils to yield as well as chemical compounds according to the plant species.

Beside, the geographical locations of our studied populations had many differences. Angioni et al. (2006) stated the composition of the essential oil has been varying according to the region, soil type and environmental conditions from where the plant species have been collected. For example, studies showed that the essential oil compositions of Artemisia herba-alba varied between the populations, therefore the geographical locations and climatic conditions have a strong effect on it (Mighri et al. 2010; Belhattab et al. 2014).

1,8 -Cineole is the main compound of essential oil of Dizin population. Its percentage was more than $55 \%$ of essential oil compositions. The compound was seen as a major or minor constituent occurring in different aromatic herbs, such as Mentha longifolia L., Origanum vulgare L., Rosmarinus officinalis L., Thymus vulgaris L. (Lamiaceae), Artemisia dracunculus L. (Compositae), Coriandrum sativum L. (Umbelliferae), and also Zingiber officinale Rosc. (Zingiberaceae) (van Vuuren and Viljoen 2007).

Therefore, changes in essential oil compositions leading to variations in medicinal properties of this species. Because, previous reports showed that 1, 8-Cineole had multiple usages in food as well as medicinal industries. For example, the compound employed as a flavoring agent for food products and treatment of infectious respiratory disorders in folk medicine. Moreover, the compound is used in the pharmaceutical industry for formulations of drug (Santos and Rao 2001). Investigations have proved 
different properties, like anthelmintic (Shah et al. 2011), antimicrobial (Krist et al. 2008), antimalarial ( $\mathrm{Su}$ et al. 2008), insecticidal (Prates et al. 1998), antifungal (Pattnaik et al. 1997), antioxidant, cytotoxic and antitumor (Asanova et al., 2003), antispasmodic, anti-inflammatory and analgesic (Santos and Rao, 2000), and gastroprotectant (Santos and Rao 2001).

Three isomers of nepetalactone were observed in essential oil of Dizin population. The constituent is one of the main compounds of essential oils of many Nepata species such as $N$. assurgens, $N$. cadmea, N. caesarea, $N$. cephalotes, $N$. crassifolia, $N$. x faassenii, $N$. govaniana, $N$. mirzayanni, $N$. persica, $N$. racemosa and $N$. teydea (Sharma and Cannoo 2013). However, no isomer of this compound was observed in Polor population essential oil. This condition was observed in former examinations on different populations of Nepeta taxa. For instance, Sharma and Cannoo (2013) reported most of the species growing in the Himalayas region have been contained compounds other than nepetalactone as major constituents in their essential oils as compare to the species growing in other parts of the world, which have both nepetalactone along with its derivatives and other than nepetalactone compounds as the major ingredient of their essential oils.

In conclusion, the obtained data showed that the essential oil compositions as well as amount widely varied between the studied populations. Since these populations were selected from different habitats that have various ecological conditions, it seems that the environmental factors have strong effects on type as well as percents of essential oil compositions and also its amount. Therefore, the medical properties of medicinal herbs, which related to their essential oils compositions, are not stable between different samples of the same species. In addition, for each chemotaxonomic treatment, especially at infrageneric level, some populations of each taxon must be examined.

\section{REFERENCES}

Angioni A, Barra A, Coroneo V, Dessi S, Cabras P, 2006. Chemical composition, seasonal variability, and antifungal activity of Lavandula stoechas L. ssp. stoechas essential oils from stem/leaves and flowers. J Agric Food Chem 54(12): 4364-4370.

Asanova ZK, Suleimenov EM, Atazhanova GA, Dembitskii AD, Pak RN, Dar A, Adekenov SM, 2003. Biological activity of 1, 8-cineole from levant wormwood. Pharma Chem J 37(1): 28-30.

Avci AB. 2011. Chemical variation on the essential oil of Thymus praecox ssp. scorpilii var. Laniger. Int J Agric Biol 13:607-610.

Baser KHC, Oözek T, Yildiz B, Bahcecioglu Z, TuümenG. 2000 Composition of the essential oil of Nepeta fissa CA Meyer. J Essent Oil Res 12(1):27-28.

Belhattab R, Amor L, Barroso JG, Pedro LG, Figueiredo AC. 2014.Essential oil from Artemisia herba-alba Asso grown wild in Algeria: Variability assessment and comparison with an updated literature survey. Arab J Chem 7(2): 243-251.

Degenhardt J, Köllner TG, Gershenzon J. 2009. Monoterpene and sesquiterpene synthases and the origin of terpene skeletal diversity in plants. Phytochemistry 70(15): 1621-1637.

Dudareva N, Klempien A, Muhlemann JK, Kaplan I. 2013. Biosynthesis, function and metabolic engineering of plant volatile organic compounds. New Phytol 198(1):16-32.
Figueiredo AC, Barroso JG, Pedro LG, Scheffer JJ. 2008. Factors affecting secondary metabolite production in plants: volatile components and essential oils. Flavour Fragr J 23(4): 213-226.

Haider F, Kumar N, Banerjee S, Naqvi AA, Bagchi GD. 2009. Effect of altitude on the essential oil constituents of Artemisia roxburghiana Besser var. purpurascens (Jacq.) Hook. J Essent Oil Res 21(4):303304.

Jamzad Z. 2012. Flora of Iran, no. 76, Lamiaceae. Research Institute of Forest and Rangelands, Tehran, Iran.

Kofidis G, Bosabalidis AM, Moustakas M. 2003. Contemporary seasonal and altitudinal variations of leaf structural features in oregano (Origanum vulgare L.). Ann Bot 92(5):635-645.

Krist S, Sato K, Glasl S, Hoeferl M, Saukel J. 2008. Antimicrobial effect of vapours of terpineol,(R)-(-)-linalool, carvacrol,(S)-()-perillaldehyde and 1, 8-cineole on airborne microbes using a room diffuser. Flavour Fragr J 23(5): 353-356.

Lakusic D, Ristic M, Slavkovska V, Sinzar-Sekulic J, Lakusic B. 2012. Environmental-related variations of the composition of the essential oils of rosemary (Rosmarinus officinalis L.) from the Balkan Penninsula. Chem Biodivers 9:1286-1302.

Marčetić MD, Lakušić BS, Lakušić DV, Kovačević NN. 2013. Variability of the root essential oils of Seseli rigidum Waldst. \& Kit. (Apiaceae) from Different Populations in Serbia. Chem Biodivers10(9):16531666

Mighri H, Akrout A, El-Jeni H, Zaidi S, Tomi F, Casanova J, Neffati M. 2010. Composition and intraspecific chemical variability of the essential oil from Artemisia herba-alba Growing Wild in a Tunisian Arid Zone. Chem Biodivers 7(11):2709-2717.

Mozaffarian V. 1996. A Dictionary of Iranian Plant Names. Farhang Moaser, Tehran, Iran.

Pattnaik S, Subramanyam VR, Bapaji M, Kole CR. 1996. Antibacterial and antifungal activity of aromatic constituents of essential oils. Microbios 89(358): 39-46.

Pojarkova AI. 1954. Flora of the U.S.S.R. Moscow, Vol. 20, Izdatel'stvo Akademii Nauk SSSR.

Prates HT, Santos JP, Waquil JM, Fabris JD, Oliveira AB, Foster JE. 1998. Insecticidal activity of monoterpenes against Rhyzopertha dominica (F.) and Tribolium castaneum (Herbst). Journal of Stored Products Research 34(4):243-249.

Rahimmalek M, Tabatabaei BES, Etemadi N, Goli SAH, Arzani A, Zeinali H. 2009. Essential oil variation among and within six Achillea species transferred from different ecological regions in Iran to the field conditions. Indust Crop Prod 29(2):348-355.

Santos FA, Rao VSN. 2000. Antiinflammatory and antinociceptive effects of 1,8-cineole a terpenoid oxide present in many plant essential oils. Phytother Res 14(4):240-244.

Santos FA, Rao VSN. 2001. 1, 8-cineol, a food flavoring agent, prevents ethanol-induced gastric injury in rats. Dig Dis Sci 46(2):331-337.

Sefidkon F, Dabiri M, Alamshahi A. 2002. Analysis of the essential oil of Nepeta fissa CA Mey from Iran. Flavour Fragr J 17(2):89-90.

Shah AJ, Gilani AH, Abbas K, Rasheed M, Ahmed A, Ahmad VU. 2011. Studies on the chemical composition and possible mechanisms underlying the antispasmodic and bronchodilatory activities of the essential oil of Artemisia maritima L. Arch Pharm Res 34(8):12271238 .

Sharma A, Cannoo DS. 2013. Phytochemical composition of essential oils isolated from different species of genus Nepeta of Labiatae family: A review. Pharmacophore 4 (6): 181-211.

Su V, King D, Woodrow I, McFadden G, Gleadow R. 2008. Plasmodium falciparum growth is arrested by monoterpenes from eucalyptus oil. Flavour Fragr J 23(5):315-318.

Van Vuuren SF, Viljoen AM. 2007. Antimicrobial activity of limonene enantiomers and 1,8-cineole alone and in combination. Flavour Fragr J 22(6):540-544.

Zouari N. 2013. Essential oils chemotypes: a less known side. Med Aromat Plants 2:145.

Zouari N, Ayadi I, Fakhfakh N, Rebai A, Zouari S. 2012. Variation of chemical composition of essential oils in wild populations of Thymus algeriensis Boiss. et Reut., a North African endemic Species. Lipids Health Dis 11(1):28.

Zouari S, Ayadi I, Fakhfakh N, Jdir H, Aloui L, Kossentini M, Rebai A, Zouari N. 2014. Essential oil variation in wild populations of Artemisia saharae (Asteraceae) from Tunisia: chemical composition, antibacterial and antioxidant properties. Bot Stud 55(1): 76. 